Boise State University

ScholarWorks

Literacy, Language, and Culture Faculty

Publications and Presentations

9-2019

Critical Analysis of Research on the Impact of Visual Literacy for

Learning: Strengths, Weaknesses and Recommendations for Improvement

Daibao Guo

Boise State University

Wendi Zimmer

Texas A\&M University

Sharon D. Matthews

Texas A\&M University

Erin M. McTigue

University of Stavanger 
This is an author-produced, peer-reviewed version of this article. The final, definitive version of this document can be found online at Journal

of Visual Literacy, published by Routledge. Copyright restrictions may apply. doi: 10.1080/1051144X.2019.1611702

The Impact of Visual Displays on Learning across the Disciplines: A Systematic Review

\author{
Daibao Guo $^{\text {a }}$
}

Erin M. McTigue ${ }^{b}$

Sharon D. Matthews ${ }^{c}$

Wendi Zimmer ${ }^{\mathrm{c}}$

${ }^{\text {a }}$ Department of Literacy, Language, \& Culture

Boise State University

Bosie, ID

daibaoguo@boisestate.edu

${ }^{\mathrm{b}}$ Norwegian National Centre for Reading and Reading Research

University of Stavanger

Stavanger, Norway

erin.m.mctigue@uis.no

${ }^{\mathrm{c}}$ Department of Teaching, Learning, \& Culture

Texas A\&M University

College Station, TX

sharon.matthews@tamu.edu

wzimmer@tamu.edu 
This is an author-produced, peer-reviewed version of this article. The final, definitive version of this document can be found online at Journal of Visual Literacy, published by Routledge. Copyright restrictions may apply. doi: 10.1080/1051144X.2019.1611702

Running head: THE IMPACT OF VISUAL DISPLAYS ACROSS DISCIPLINES

\begin{abstract}
The current systematic review aimed to investigate in what ways the incorporation of visual display tasks benefits K-12 students' content-area learning. After screening 1693 articles at abstract level and a systematic evaluation of methodological quality, we synthesized 44 articles for this review. The qualitative synthesis of the studies is organized by categories of interaction with visual displays (ViDis), instructional support, and types of knowledge and learning. Overall findings indicate the simple inclusion of visual displays does not guarantee a positive learning effect. More detailed findings distinguish three categories of ViDis: author-provided, studentfilled-in, and student-created visual displays. Furthermore, we discuss each category's effectiveness for students' learning. Additionally, findings on retention and information comprehension are mixed when students are either provided with ViDis or complete ViDis themselves. However, the integration of ViDis in K-12 classrooms indicate highly promising results for enhancing students' higher-level learning (i.e., analyzing, evaluating, applying, and creating). Finally, we provided practical implications for K-12 teachers and recommendations for future research.
\end{abstract}

Keywords: graphics, visual displays, learning, systematic review 
This is an author-produced, peer-reviewed version of this article. The final, definitive version of this document can be found online at Journal of Visual Literacy, published by Routledge. Copyright restrictions may apply. doi: 10.1080/1051144X.2019.1611702

\section{The Impact of Visual Displays on Learning across the Disciplines: A Systematic Review}

Visual Displays (ViDis), in traditional and multimedia formats, have long been used in the K-12 context, particularly in support of content-area learning. With rapid progress in computing and publishing, visual presentations, whether in physical texts or online, have become increasingly prevalent and complex. For example, when learning biology, a student may have once encountered a simple black and white diagram of a human body, they are now more likely to view a hybrid representation of a photograph of a human body with cutaways, insets, and labels (Authors, 2018; Fingeret, 2012). Unfortunately, movements towards visual complexity outpaces our research on such ViDis (Authors, 2018). Also contributing to complexity, it is important to recognize that ViDis rarely serve as a single source of information but are more typically combined with other sources, including texts, equations, and other ViDis (e.g., a geographical map and a data table) (Renkl \& Scheiter, 2017). Therefore, ViDis are often part of a complex learning process, mirroring the multiple document learning context described in online reading (Britt \& Gabrys, 2001). Therefore, we argue it is timely to consolidate what we do know from research, and where we need more knowledge. In short, do students learn well from modern ViDis?

Historically, there has been little consistency for terminology of instructional graphics. Attempts to categorize have traditionally been binary in nature, positioning nonrepresentational pictures (abstract representations) in contrast to representational pictures (photography and drawings) (Levie \& Lentz, 1982); or monosemic (i.e., diagrams, charts, tables) in contrast to polysemic (i.e., images, photographs) representations (Bertin, 1983); or diagrammatic, (abstract graphics) in contrast to isogrammatic (photography and drawings) (Hunter, Crismore, \& Pearson, 1997). However, due to the shift towards visual complexity, in which photographs may 
This is an author-produced, peer-reviewed version of this article. The final, definitive version of this document can be found online at Journal of Visual Literacy, published by Routledge. Copyright restrictions may apply. doi: 10.1080/1051144X.2019.1611702

be overlaid with a diagram, these binary categories are rendered insufficient. As such, following Renkle and Scheiter's (2017) lead, for this review, we rely on the more general category of ViDis, which we define as graphical texts (in contrast to word-based texts), that capitalize on spatial organization as well as visual representations. ViDis can be dynamic, such as animations, simulations, and videos, but in our work, we consider only static displays. However, when summarizing others' research, we also use the terminology of visuals and graphics interchangeably with ViDis, in order to reflect the original work.

Findings suggest students need support (e.g., scaffolding, instruction, modeling) to fully extract and integrate the information within ViDis for content learning, and additional strategies to approach complex ViDis (Authors, 2010; Cromley et al., 2016a; DiCecco \& Gleason, 2002; Kwon \& Cifuentes, 2009). Unfortunately, compared to text comprehension, visuals receive relatively limited research attention. As a result of this limited attention, the research progress in the visual aspects of literacy has been, at times, unsystematic and frequently inconclusive for educators. Thus, the current study, using the systematic review methodology, aims to synthesize the current body of research, regarding the impact of ViDis on K-12 students' content-area learning. Due to our focus of visuals in the service of learning and instruction (rather than evaluating visuals for aesthetics, communication, bias, etc.), we approached this research through a pragmatic lens, valuing research for its practical use and success. As such, our reviewed literature corpus includes multiple theoretical stances, although the majority of research reviewed derives from a cognitivist approach.

\section{Conceptualizing the Review}

\section{Rationale and Importance of this Review}

Although increasing evidence indicates that the addition of ViDis contributes to students' 
This is an author-produced, peer-reviewed version of this article. The final, definitive version of this document can be found online at Journal of Visual Literacy, published by Routledge. Copyright restrictions may apply. doi: 10.1080/1051144X.2019.1611702

THE IMPACT OF VISUAL DISPLAYS FOR LEARNING ACROSS DISCIPLINES

learning (Norman, 2012; Roberts, Norman, \& Cocco, 2015), findings in the field can be contradictory. For instance, selected studies show presenting ViDis to students, even without corresponding instruction, benefits reading comprehension (Hannus \& Hyönä, 1999; Mayer \& Gallini, 1990). However, other researchers (Authors, 2010) found students often misunderstand elements of abstract ViDis (e.g., the arrows in a flow diagram). Furthermore, subsequent research concludes that simply providing students ViDis may have no impact on students' learning or could hinder their reading comprehension (Authors, 2009; Brookshire, Scharff, \& Moses, 2002). As such, these researchers recommend more active interventions that focus on the process of learning from graphics rather than manipulating the graphics themselves. Such mixed results also provide few clear guidelines for ViDis instructional use.

Additionally, it is not clear why researchers often derive inconsistent conclusions from graphics. The increasing graphical complexity may partially account for the disparity of findings, such as those in modern texts, in which visuals are rarely presented singularly within a page of linear text (Fingeret, 2012). The typical layout of informational texts has undergone recent changes, as evidenced by the advent of more online reading of digital texts. Even traditional print textbooks are less likely to be formatted in a linear arrangement. As such, the majority of informational texts students encounter are increasingly multimodal in nature (Authors, 2018; Fingeret, 2012). For example, a paragraph on trees may have, not one, but a series of corresponding images, each illustrating a different leaf type. However, the texts used in oftencited research studies from previous decades (e.g., Mayer \& Gallini, 1990; Hannus \& Hyona, 1999) do not mirror such modern texts because researchers traditionally paired linear texts with a single graphic or single graphic per page. Our current work attempts to address this disparity by reviewing only more modern research (from 2002 forward). We work to provide rich 
descriptions of the types of text and graphics within reviewed studies rather than treating them as a singular construct.

Furthermore, theory and research does not yet provide clear guidance on how to best visually illustrate content across varying disciplines. While specific learning theories, such as dual coding theory (Paivio, 1971; 1986), predict visuals support the learning process, such theories do not predict the specific nature of how visuals and texts should be designed. Meanwhile, researchers also document that adding ViDis in informational text also adds new comprehension challenges for young readers (Authors, 2010; Roberts \& Brugar, 2017). When reading visually complex texts, readers must apply multiple literacy skills to select, interpret, and integrate information provided in both the text and ViDis. These processes may lead to cognitive overload during reading, particularly for younger and less skilled readers (Authors, 2011; Duke \& Bennett-Armistead, 2013).

To ensure better cost-benefits of graphics for comprehension, researchers have engaged in establishing graphical design principles (e.g., Mayer, 2001; 2008) which could assist teachers in selecting or designing appropriate visuals. For example, such graphical design principles recommend a close alignment of ViDis and the corresponding text (Mayer, 2001). However, while empirically based, Mayer's work primarily draws upon highly controlled research with skilled adult readers (i.e., college students) reading technical texts and may not directly apply to younger students or other text genres (Authors, 2009; Sun \& Lee, 2016). Consequently, limited research supports teachers in selecting appropriate visual materials or improving younger students' content-area learning from visuals.

Not surprisingly, this gap between research and K-12 reading and instruction has created a situation in which classroom visual graphic instruction (if occurring) is frequently uninformed 
This is an author-produced, peer-reviewed version of this article. The final, definitive version of this document can be found online at Journal of Visual Literacy, published by Routledge. Copyright restrictions may apply. doi: 10.1080/1051144X.2019.1611702

by research (Authors, 2011). As a result, students have often not fully acquired visual literacy skills before being expected to independently make sense of visually-dense informational texts (Roberts \& Brugar, 2017). This disconnect is not the fault of teachers, but reflects an incomplete, or not fully synthesized, research base, which again, we aim to partially address in this study. The need for such work is immediate, because even with an incomplete research base, teachers are responsible for content-area instruction which includes many ViDis.

\section{Relevant Literacies}

The concept of a singular literacy has expanded to new literacies or multiple literacies, and our work occurs at the overlap of three: visual literacy, content-area literacy, and disciplinary literacy. Visual literacy is the broadest of these three literacies which we define from a synthesis of other scholars (e.g., Metros, 2008; Robinson, 1984; Wileman, 1993) as the ability to read, interpret, evaluate, and produce visual information and therefore transcends content areas. However, in our work, we focused on visuals for the purpose of learning content material. Therefore, expanding from Vacca and Vacca (2005), we define content-area literacy as the ability to read, write, speak, view, and listen to learn subject matter in a given discipline (e.g., Math, English, Science, Social Studies). As such, content-area literacy prioritizes generic skills such as summarization and concept mapping, which can be used to learn across content. Therefore, graphic organizers are a classic content-area literacy approach. However, according to Shanahan and Shanahan (2008), content-area literacy represents an intermediate skill set which supports disciplinary literacy, referring to the more advanced literacy skills that “[specialize] to history, science, mathematics, literature, or other subject matter" (p. 44). Accordingly, visuals are used uniquely in each discipline (Shanahan \& Shanahan, 2008). A scientist creating a diagram to plan an experiment would, therefore, be an example of 
This is an author-produced, peer-reviewed version of this article. The final, definitive version of this document can be found online at Journal of Visual Literacy, published by Routledge. Copyright restrictions may apply. doi: 10.1080/1051144X.2019.1611702

disciplinary literacy, rather than content-area literacy. In this work, while we searched for examples of both content-area literacy and disciplinary literacy, it should be noted that more of the studies would be categorized as content-area literacy.

Within the U.S., greater attention has been given within learning standards for both the interpretation and production of ViDis in content areas. For example, in the Common Core State Standards (CCSS, 2009), the national academic standards adopted by a majority of the states, describes how teachers should deliver visual literacy instruction to facilitate students' contentarea learning. For instance, when teaching young readers (e.g., $4^{\text {th }}$ grade students), teachers should provide support to facilitate students' abilities to “interpret information presented visually, orally, or quantitatively (e.g., in charts, graphs, diagrams, time lines, animations, or interactive elements on Web pages) and explain how the information contributes to an understanding of the text in which it appears" (CCSS, 2009). Within states that chose not to adopt the CCSS, analogous standards mirror the focus on ViDis in content areas. For example, in Grade 5, Texas Essential Knowledge and Skills for Science (standards adopted in the state of Texas), students are tasked to show their knowledge through drawing and developing models, as well as constructing tables, charts, bar graphs, and maps to organize and evaluate data (TEA, 2017). Therefore, an increasing call exists for researchers to examine effective visual graphic instruction for younger students. Specifically, in what ways the incorporation of visual graphic tasks (i.e., any learning tasks involving ViDis) could benefit K-12 students' content-area learning?

Finally, this review focused on the impact of ViDis on the cognitive domain of learning. Extended from definitions of learning, a student learning outcome is described as significant and essential learning that students have achieved. Despite the fact that the role of ViDis in learning 
This is an author-produced, peer-reviewed version of this article. The final, definitive version of this document can be found online at Journal of Visual Literacy, published by Routledge. Copyright restrictions may apply. doi: 10.1080/1051144X.2019.1611702

THE IMPACT OF VISUAL DISPLAYS FOR LEARNING ACROSS DISCIPLINES

has been the focus of previous reviews (e.g., Carney \& Levin, 2002; Renkl \& Scheiter, 2017;

Vekiri, 2002), and Mayer's (2001) findings indicate visuals promote certain learning types more than others, limited studies explicitly distinguished levels of learning outcomes. Therefore, in the current study, we operationalize learning outcomes through a brief historical perspective. Bloom and colleagues (1956) distinguished cognitive learning outcomes into six categories: knowledge, comprehension, application, analysis, synthesis, and evaluation. More recently, Anderson and colleagues (2001) modified Bloom's taxonomy, proposing a new classification of cognitive effort, reflecting a more active form of engagement: remembering, understanding, applying, analyzing, evaluating, and creating.

\section{Context of Previous Reviews}

In past decades, the focus of research reviews has shifted from exploring the nature of ViDis and investigating students' characteristics, to visual graphic instruction (Carney \& Levin, 2002; Peeck, 1993; Renkl \& Scheiter, 2017; Vekiri, 2002). These reviews informed the current study. In the following section, we present key findings from each review and then position the need for this review within the previous studies.

Vekiri's (2002) qualitative review of research mainly examined the roles of graphics in learning from three theoretical perspectives: dual coding theory (Clark \& Paivio, 1991), visual argument theory (Waller, 1981), and conjoint retention theory (Kulhavy et al., 1993; 1994). Under these theoretical frameworks, Vekiri (2002) synthesized relevant research and concluded display characteristics (e.g., type, function, and complexity) and learners' characteristics (e.g., content knowledge, prior knowledge, and visual-spatial ability) influenced the effects of ViDis. Findings further indicated graphics are beneficial only when they allow learners to integrate information with appropriate cognitive loads. 
This is an author-produced, peer-reviewed version of this article. The final, definitive version of this document can be found online at Journal of Visual Literacy, published by Routledge. Copyright restrictions may apply. doi: 10.1080/1051144X.2019.1611702

THE IMPACT OF VISUAL DISPLAYS FOR LEARNING ACROSS DISCIPLINES

Unlike Vekiri (2002), Carney and Levin (2002) quantified the visual facilitation in terms of functions (i.e., decorative, representative, interpretational, organizational, and transformative) that pictures serve in text processing. They identified transformational graphics (visuals mainly used to enhance readers' retention of content by presenting the information in a more vivid way) as the most meaningful and interactive visuals because they improved students' recall of text information. Other illustrations, such as representational, organizational, and interpretational pictures, had medium to large positive effects on students' text-learning (Hedges' $g=0.5,0.7$, 0.75 respectively). However, this research mainly concentrated on graphic characteristics, providing little insight regarding potential effects of learner differences and classroom interventions.

Renkl and Scheiter (2017) attempted to address the research gap by distinguishing between material-oriented interventions (i.e., form) and learner-oriented interventions (i.e., function). In material-oriented interventions, researchers evaluated visual design effectiveness by managing visual complexity. For learner-oriented interventions, researchers examined three intervention types: training (i.e., providing courses or interventions), pre-training (i.e., providing content-related information prior to the learning phase), and promoting (i.e., using prompts as strategy activators to induce learning strategies). Among these learner-oriented interventions, the training interventions proved consistently successful, and the pre-training interventions indicated promise but were less studied. The materials-oriented interventions demonstrated potential benefit as well, but the authors noted research was conducted in laboratory settings and not in authentic classrooms.

More recently, in a meta-analysis, Authors (2017) evaluated the impact of ViDis on reading comprehension and potential moderator effects of learner and task variables. Findings 
revealed including graphics had a moderate overall positive effect $($ Hedges' $g=0.39)$ on students' reading comprehension, regardless of grade level. When compared to mixed graphical presentations (i.e., studies used more than two types of graphics together, such as diagrams and pictures), pictures proved more effective, indicating visual complexity may challenge readers' comprehension.

Although these four reviews are unique in content, they frame a need for the current study. Specifically, Vekiri (2002) and Carney and Levin (2002) published their studies over a decade ago, limiting their research scope, as they mainly focused on traditional representations, providing little information regarding multimedia format visuals. Moreover, both reviews attempted to establish graphic design principles with a focus on researcher-designed graphics. However, with the increasingly complex graphics presented in modern textbooks, there is a call for investigating authentic materials that today's students encounter in classrooms. Finally, Vekiri's review focused on three specific theoretical approaches, while we took a more pragmatic coding approach for theory without limiting our research base, a priori, to specific theories.

Shifting to more recent work, Renkl and Scheiter's (2017) focused on interventions but did not systematically consider factors such as students' grade level, testing language, and learning outcomes, which potentially moderate the graphics' effectiveness (e.g., Authors, 2009; Roberts, Norman, \& Cocco, 2015). Furthermore, previous reviews did not follow overall systematic protocols. Although Vekiri specified an inclusion criteria, zero previous reviews documented their search process in a replicable manner.

Finally, although our recent meta-analytic review (Authors, 2017) made progress in answering the "why", "when", and "for whom" of picture facilitation, due to the constraints 
endemic to meta-analysis, we excluded many studies for methodological reasons and process data could not be thoroughly analyzed. Specifically, we could not capture research using thinkaloud and eye-tracking methods. Therefore, this current study aimed to extend the focus of previous reviews by employing the more comprehensive methodology of systematic review, allowing us to include multiple types of empirical studies and generate themes through qualitative analyses. Our study is guided by the central question: In what ways does the incorporation of visual display tasks benefit K-12 students' content-area learning? We further split our main research question into three specific questions as follows:

a. How does interacting with visual displays impact students' content-area learning?

b. Under what conditions (e.g., content, strategies, activities, and duration) do visual displays enhance students' learning?

c. In what ways does the incorporation of visual display tasks benefit students' various types of learning?

\section{Method}

A methodological approach of systematic literature review (e.g., Authors, 2016; Risko et al., 2008) was applied to evaluate the quality of included studies and synthesize the empirical research findings associated with the impact of ViDis on K-12 students' learning across disciplines. In summary, we applied a four-step process: (a) identifying and searching articles with a combination of multiple key terms, (b) screening studies using predetermined selection criteria, (c) coding studies and evaluating methodological quality of research based on quality indicators, and (d) analyses of the included studies (e.g., Miller, Cromley, \& Newcombe., 2016; Risko et al., 2008). As previously mentioned, rather than simply quantifying effect sizes from 
This is an author-produced, peer-reviewed version of this article. The final, definitive version of this document can be found online at Journal of Visual Literacy, published by Routledge. Copyright restrictions may apply. doi: 10.1080/1051144X.2019.1611702

THE IMPACT OF VISUAL DISPLAYS FOR LEARNING ACROSS DISCIPLINES

quantitative studies, this methodological approach allowed us to incorporate findings from multiple types of empirical research (e.g., quantitative, qualitative, and mixed methods). Additionally, through a systematic evaluation of methodological quality of studies, we only included research with rigorous study design. Figure 1 presents the sample retrieval and identification process.

[Figure 1 about here]

\section{Literature Search}

This study concentrated on empirical articles published between January 2002 and October 2017. Studies published before 2002 were included in previous systematic reviews (Carney \& Levin, 2002; Vekiri, 2002), and therefore, are not a focus of this review.

We identified relevant articles by conducting searches in the following databases: ERIC (ProQuest), PsycINFO, and Education Source, using a combination of a set of terms: visual graphics (including picture, diagram, image, table, timeline, photograph, flowchart, map, visual display, and adjunct display), K-12 students (e.g., elementary and secondary students,), and learning. The intent of this search was to locate all eligible studies for further analysis, yielding 1677 total articles.

\section{Selection Criteria}

The screening and coding process involved two steps, abstract-level and full screening.

First, we screened all articles at the title and abstract level, using the following selection criteria: (a) examined empirically; (b) published in a peer-reviewed journal; (c) measured students' cognitive learning process and/or outcomes; (d) conducted in K-12 education context; (e) involved a graphic task; (f) primarily focus on the use of ViDis across disciplines; (g) studies using video, audio, simulation, and computer games were excluded. After the abstract-level 
This is an author-produced, peer-reviewed version of this article. The final, definitive version of this document can be found online at Journal of Visual Literacy, published by Routledge. Copyright restrictions may apply. doi: 10.1080/1051144X.2019.1611702

THE IMPACT OF VISUAL DISPLAYS FOR LEARNING ACROSS DISCIPLINES

screening, we identified 173 articles that met the selection criteria, therefore, qualifying them for full screening. Moreover, to extend the search parameters, we also conducted an ancestral search by examining previous reviews’ reference lists (e.g., Renkl \& Scheiter, 2017). We identified 16 additional articles in this tertiary step. After we removed irrelevant articles and those not meeting our inclusion criteria, 88 articles remained.

\section{Methodological Quality Evaluation}

As described by Cooper (1982), in the evaluation stage of systematic reviews, after data is collected "critical judgments are made about the quality of individual data points" (p. 296). To evaluate the methodological quality of multiple types of empirical studies and identify validity threats, we modified the screening guidelines established by Risko and colleagues (2008). Our screening tool included six methodological quality indicators (MQIs) addressing three quality dimensions: (a) theoretical alignment; (b) the clarity, reliability, and validity of research; and (c) the consistency and appropriateness of the study's findings. Furthermore, the six MQIs correspond to scores ranging from 1 to 8 . Specifically, we rated and scored the included studies using the following scale and criteria: high-quality studies scored 7-8; moderatequality studies scored 4-6, and low-quality studies scored 1-3. Adopting the MQIs allowed us to only include high-quality studies for further analysis (see Authors, 2019).

To establish interrater-reliability, we randomly selected $26 \%$ of the entire sample $(n=23)$ for double coding. The inter-rater reliabilities on MQIs standard 1, 2, and 3 were 100\%, 90.22\%, and $97.8 \%$, respectively. The overall inter-rater reliability was $94.6 \%$. Based on evaluation at the full-text level, we found $27.27 \%$ of the 88 articles received a score of $6,11.36 \%$ a score of 5 , and $10.23 \%$ a score of 4 , respectively. In summary, this step eliminated $50 \%$ of selected articles, with 44 articles remaining in the database. 
Notably, five articles (i.e., Cromley et al., 2016; Lenzner, Schnotz, \& Müller, 2013;

Leopold, Doerner, Leutner, \& Dutke, 2015; Moreno, Ozugul, \& Reisslein, 2011; Schmeck, Mayer, Opfermann, Pfeiffer, \& Leutner, 2014) included more than one study that met our research purpose. For instance, Lenzner, Schnotz, and Muller (2013) conducted three experiments. In the first study, they provided students ViDis with different functions (e.g., informational and representative) and employed an eye-tracking technique to evaluate students reading process. Whereas in the second study, Lenzner and colleagues (2013) examined the effects of visuals on affective learning. In the third study, they evaluated the impact of using informational and representative graphics together. After a careful evaluation using the inclusion criteria, we included both the first and third study in our analyses. In total, we analyzed 44 articles, including 49 studies.

\section{Analysis and Interpretation Stage}

To answer our main research question: In what ways, does the incorporation of visual graphic tasks benefit K-12 students' content-area learning?, we synthesized the results of the included 49 studies. We first analyzed the descriptive characteristics to extract general research trends regarding visual tasks and learning. This analysis allowed us to identify any conceptrelevant operations or constructs that were not initially considered as research questions (Cooper, 1982). Then we synthesized the reviewed studies to answer our three specific questions: (a) How does interacting with visual displays impact students' content-area learning?; (b) Under what conditions (e.g., content, strategies, activities, duration) do visual displays enhance students' learning?; (c) In what ways does the incorporation of visual display tasks benefit students' various types of learning?.

We conducted an inductive paradigmatic analysis (Polkinghorne, 1995) to identify 
This is an author-produced, peer-reviewed version of this article. The final, definitive version of this document can be found online at Journal of Visual Literacy, published by Routledge. Copyright restrictions may apply. doi: 10.1080/1051144X.2019.1611702

THE IMPACT OF VISUAL DISPLAYS FOR LEARNING ACROSS DISCIPLINES

categories, allowing us to encompass the varied themes across studies in a logical manner.

Borrowed from Risto et al. (2008) and Authors (2018), we first extracted descriptive information (e.g., participant characteristics, study design, learning outcomes) from reviewed studies.

Appendix A presents key codes of this research synthesis. After determining key information and main findings from all studies, we used the descriptive information as tentative codes.

Furthermore, we compared the similarities and differences of the codes, categorizing them to generate common themes in relation to the three research questions - in other words, we grouped studies topically first. This approach offered two inherent methodological advantages. First, it allowed for the inclusion and synthesis of empirical studies with various study designs (i.e., qualitative, quantitative, and mixed-method studies). Secondly, rather than predetermining the themes, we analyzed studies in an inductive manner, allowing us to capture the complex features of reviewed research and categorize them into broader themes.

As a final layer, we then returned to the different categories of study design and present findings (within themes) by study design. In this manner, any interaction between study design and results can be considered, and effect sizes (ESs) can be presented across multiple similar quantitative studies, allowing for greater specificity. We organized all experimental and quasiexperimental studies, which included a control group (text-only) and at least one intervention group (ViDis and text). We considered studies that either reported ESs or provided sufficient quantitative information that allows us to calculate ESs (e.g., standardized mean, standardized deviation, and sample sizes).

In the majority of studies, researchers compared the learning outcomes (in the post-tests) of an intervention group with those of a control group, to report the effectiveness of ViDis design, intervention, or support (e.g., strategies/activities). As shown in Appendix B, in some 
cases, we reported multiple ESs from one study if the study investigated more than one type of learning (e.g., comprehension and application), or if the study included a control group and multiple intervention groups, with multiple comparisons (e.g., see Kwon \& Cifuentes, 2009). Reporting the individual ES (rather than a weighted ES) allows us to present the variations of the study design in terms of different learning outcomes, intervention, and effects of ViDis design. Please note that several studies were reported more than once in the table due to different themes of our research interests. For example, in the second study, Schmeck and colleagues (2014) assigned students to three conditions: (a) the author-provided ViDis and text; (b) student-created ViDis and text; and (c) control group (text-only). In Appendix B, under the category/theme titled “Learning by viewing: Using author-provided ViDis”, we reported the ES from Schmeck et al's (2014) study, by comparing the author-provided ViDis group with the control group (text-only). Under the category/theme titled "Learning by creating: Student-created ViDis", we reported the ES from Schmeck et al's (2014) study again, but compared the student-created ViDis group with the control group (text-only).

Additionally, there were two groups of researchers that investigated and reported the growth of students' learning from pre- to post-test. (Bergey et al., 2015; Cromley et al., 2013a) which we also reported in Appendix B. Finally, studies that did not report ESs nor the information to calculate ESs (in the latter case we contacted authors to seek unreported information) were excluded from the table (i.e., Cohen \& Johnson, 2011; 2012; Gerstner \& Bogner, 2009). In summary, reporting the ESs in this manner allows us to precisely present the findings under each theme.

\section{Results}

\section{Descriptive Characteristics of Studies}


This is an author-produced, peer-reviewed version of this article. The final, definitive version of this document can be found online at Journal of Visual Literacy, published by Routledge. Copyright restrictions may apply. doi: 10.1080/1051144X.2019.1611702

THE IMPACT OF VISUAL DISPLAYS FOR LEARNING ACROSS DISCIPLINES

In the following section, we synthesize study characteristics, including participants, content areas, and research methodology.

Study participants. Inclusionary studies involved both elementary and secondary students. To consistently present findings, we used four designations: kindergarten and lower elementary (K-grade 3), upper elementary (grades 4-6), lower secondary (grades 7-9), and upper secondary (grades 10-12). Except for one study that recruited participants from both lower and upper elementary, studies focused on only one of these designations. In summary, of the 49 studies, 18.4\% (n=9) included kindergarten and lower elementary, 30.6\% $(n=15)$ included upper elementary, $24.5 \%(n=12)$ included lower secondary and $25.5 \%(n=12)$ focused on upper secondary students.

Content areas. Of the 49 included studies, only three focused on two disciplines (e.g., a combination of biology and geography, see Cromley et al., 2013a). Correspondingly, most studies focused on one content area in isolation $(n=46)$. Interestingly, we found over half of the studies $(54.3 \%, \mathrm{n}=25)$ researched the effect of ViDis on science learning and $19.6 \%(\mathrm{n}=9)$ focused on math. Only a small proportion of studies researched language arts (15.2\%) or social studies (6.5\%). This trend highlights the close connection between ViDis and STEM education, addressing the need for answering our main research question, in what ways ViDis tasks could facilitate students' content-area learning.

Research method. Regarding research methodology, our findings indicated a great majority of visual graphic studies used quantitative methods (69.32\%). Only a small portion of research applied qualitative research methods $(23.86 \%)$ or mixed methods $(6.81 \%)$.

\section{Synthesis of Studies}

The following section encompasses three major themes responding to our three research 
This is an author-produced, peer-reviewed version of this article. The final, definitive version of this document can be found online at Journal of Visual Literacy, published by Routledge. Copyright restrictions may apply. doi: 10.1080/1051144X.2019.1611702

THE IMPACT OF VISUAL DISPLAYS FOR LEARNING ACROSS DISCIPLINES

questions: (a) interacting with ViDis, (b) supporting or scaffolding, and (c) types of knowledge

and learning. Specifically, we first summarized findings using author-provided ViDis and student-constructed ViDis. Then we present studies focused on instruction or support regarding incorporating visual graphic tasks with content area learning. Third, we analyzed the body of included studies, which summarizes the types of knowledge and learning related to ViDis. Figure 2 presents the structure of the themes that emerged in analyses.

[Figure 2 about here]

Interacting with ViDis. There are two main ways that students can interact with ViDis either viewing or completing. It is important to recognize that viewing can be on a continuum from passive to actively working to build comprehension. According to Mayer (2001), simply providing students with ViDis may not facilitate their learning, and one approach for potentially improving learning with visuals is through material design (i.e., manipulating the presentation of a graphic to optimize learning). To extend this work, we analyzed studies focused on elementary and secondary students to better capture graphic characteristics in the K-12 context. While selected studies have investigated the functions and forms of ViDis and their impacts on students' learning (Gatto, Porter, \& Selleck, 2011; Kress \& Van Leeuwen, 1996), researchers give limited attention to how students interact with ViDis with different characteristics. For instance, compared with the author-provided mind map, having students create a mind map involves the application of a set of higher-level learning skills, which contributes to greater interaction. Therefore, in this section, we first use broader terminologies to present findings regarding interacting with ViDis and discuss how specific ViDis affect younger students' learning.

Learning by viewing: Using author-provided visuals. We found multiple groups of 
researchers used both author-provided and student-constructed visuals or compared the effects (e.g., Cohen \& Johnson, 2011; Terwel et al., 2009). Additionally, over half of the reviewed studies only focused on author-provided visuals, through which students "learn by viewing" rather than "constructing" $(\mathrm{n}=25)$. Author-provided visuals are ViDis that are pre-constructed by authors, most typical in K-12 texts, without the learner's active participation. For example, a preconstructed visual graphic could be a flow map with a color key representing the boreal bird immigration from Canada to the U.S. each year. That is not to say readers are necessarily passive when using pre-constructed ViDis, however, "when students learn from the pre-constructed displays, they generate their own understanding by internalizing information" (Vekiri, 2002, p. 266).

Within this broad category, researchers used concrete visuals such as photographs (i.e., Segers, Verhoeven, \& Hulstijn-hendrikse, 2008), and pictures (e.g., Acha, 2009; Arya \& Feathers, 2012; Marley \& Szabo, 2010; Mason, Tornatora, \& Pluchino, 2013) to illustrate the text and potentially reduce students' cognitive load (i.e., present a concrete representation of an abstract concept). However, as such ViDis are often redundant with the written text, or simply represent the content from texts, they may not effectively reduce text complexity for elementary readers or improve their learning as would ViDis with functions more aligned with comprehension. Specifically, we found two experimental studies that directly compared the effects of concrete graphic with that of text-only condition (Acha, 2009; Segers et al., 2008). Findings from both studies show that presenting representational visuals (along with texts) yield similar effects on students' learning, compared to that of using written text only (see Appendix B). 
groups of researchers demonstrated that the effectiveness of a concrete picture is also associated with students' ability to integrate information from texts and pictures. When using narrative multimodal texts, Arya and Feathers (2012) found that only when second-grade students are able to identify useful information in visuals and align visual clues with narrative text are they more capable of understanding content. Regarding informational texts, similarly, Mason, Tornatora, and Pluchino (2013) grouped fourth-grade readers based on the level with which students integrate text and visuals (similar to the alignment described by Arya and Feathers, 2012). They identified three reading patterns: high, intermediate, and low integrators. Further analyses showed the high integrator group outperformed the low integrators both on the immediate recall and factual knowledge test. Overall, these findings revealed concrete or realistic visuals are effective, only when students successfully integrate visual information with text, and such skills vary by reader.

Compared to concrete ViDis, abstract graphics or schematic ViDis, which have the primary function of organizing information, are more widely studied in the reviewed research. Although abstract graphics would ideally reduce irrelevant information and focus readers' attention on key ideas, these graphics yielded inconsistent learning effects (e.g., Leopold et al., 2015; McTigue, 2009; Schmeck et al., 2014; Zheng et al., 2008). In other words, when comparing the effectiveness of abstract graphics with that of text only, findings were discrepant (see the effect sizes in Appendix B). Furthermore, it is important to note that researchers rarely presented abstract graphics without other forms of scaffolding but worked to promote students' learning through additional elements. These elements included: (a) adding cues or signals, (b) using materials with an analogy, and (c) using mixed types of ViDis.

Adding cues or signals. Researchers have identified specific elements including captions 
This is an author-produced, peer-reviewed version of this article. The final, definitive version of this document can be found online at Journal of Visual Literacy, published by Routledge. Copyright restrictions may apply. doi: 10.1080/1051144X.2019.1611702

THE IMPACT OF VISUAL DISPLAYS FOR LEARNING ACROSS DISCIPLINES

(Cromley et al., 2013b), color codes (Berthold \& Renkl, 2009), labels (Mayer \& Johnson, 2008), and correspondence signals (e.g., arrows, zoom-ins, McTigue, 2009), which can enact such principles by emphasizing relevant information and signaling connections in informational texts. Although such purposeful design of ViDis and texts may help readers build globally coherent mental representations (Mayer, 2001), the meaningful effects on learning promotion were mixed (e.g., see Appendix B). Moreover, the positive findings may have been attenuated by additional support in the interventions (e.g., teachers' instruction and feedback on the use of ViDis). For instance, Cromley and colleagues (2013b) provided the intervention group instructions on diagram conventions, which teaches students how to read labels, titles, and captions, and how to follow arrows in the correct direction. Findings showed the intervention group had a significant growth in literal and inferential comprehension of a biology diagram $(d=0.12$ and 0.35 , respectively). However, it is unclear whether the positive effect is due to the visual design or teachers' instruction.

Using materials with analogies. To further facilitate students' deep learning and reasoning skills, two research groups provided students informational texts with prompted case explanations, using experimental and quasi-experimental design. When working with middleschool students, Cromley et al. (2016) added this component through questions about similarities and differences in science concepts. Moreover, students in the (cognitive-science-based) experimental group also received instruction on comprehending visualization and clarifying misconceptions. Findings show that the experimental group significantly outperformed the control group in the post-tests on FOSS curricula $(d=0.52, d=0.41, d=0.55)$. Similarly, Zheng and colleagues (2008) provided fourth-grade students diagrams with analogies, thus students in the analogy group could compare and distinguish the similarities between two electrical circuits 
diagrams, which shows positive impacts on recall and knowledge transfer $(d=1.20, d=1.06$, respectively). In both cases, participants improved science learning when using ViDis with analogies. ViDis can work particularly well for promoting analogical reasoning because they help a learner focus on underlying concepts (e.g., a cycle).

Using mixed types of ViDis. Other researchers provided students both pictorial ViDis and schematic visuals in informational texts (e.g., Elia, Gagatsis, \& Demetriou, 2007; Norman, 2012; Roberts, Norman, \& Cocco, 2015). For instance, Roberts, Norman, and Cocco (2015) used captioned pictures, insets, surface diagrams, cross-sectional diagrams, flow charts, timelines, and tables, aiming to test the overall effects of ViDis on third graders' reading comprehension. Findings indicated visual device comprehension strongly correlated with students' overall comprehension. When retaining the same variables, and adding the visual device comprehension variable into the model, the model accounted for $71.3 \%$ of variance. Furthermore, graphical comprehension contributed to larger variance in reading comprehension when compared with other variables such as reading accuracy and cognitive flexibility. In other words, when students had the skills to use a variety of ViDis, they comprehend the text better.

To conclude, although studies above revealed the positive effect of adding explanations, using materials with analogies, and using mixed types of ViDis, due to the small sample sizes, there is an increasing need for future endeavors to validate these conclusions.

Learning by creating: Student-constructed ViDis. Twenty-four studies examined the effects of student-constructed ViDis, of which, 11 focused on K-6 students. This result may indicate a research trend younger students are frequently involved in more complex learning tasks which required them to apply a set of higher-order learning skills (e.g., analyzing, evaluating, and creating). Alternatively, this research trend may reflect the practice of having 
younger children draw to learn, more often than older learners, even though the benefits of drawing is not age-dependent (Vinter \& Perruchet, 2000). Interestingly, previous studies did not provide a clear distinction between author-provided ViDis and student-constructed ViDis, although some ViDis may fit in both categories. In the following section, we first distinguish two types of student-constructed ViDis (student-filled-in and student-created), then present findings regarding visual effectiveness.

Student-filled-in ViDis. Multiple researchers provided students with pre-drawn, abstract visuals, such as graphic organizers (e.g., Boulineau et al., 2004; Ciullo, Falcomata, Pfannenstiel, \& Billingsley, 2015; Ciullo, Falcomata, \& Vaughn, 2015; DiCecco \& Gleason, 2002; Sun \& Chen, 2016) and incomplete diagrams (e.g., Swanson, 2015). Within this category, the majority of studies explored the effects of student-filled-in ViDis on learners with different learning disabilities, such as reading disability (i.e., Boulineau et al., 2004; Ciullo, Falcomata, Pfannenstiel, \& Billingsley, 2015; Ciullo, Falcomata, \& Vaughn, 2015), math learning disability (Swanson, 2015), and general learning disability (DiCecco \& Gleason, 2002). However, only two studies focused on typically achieving students (i.e., Cromley et al., 2013a; Sun and Chen, 2016) and one on high achieving students (i.e., Gerstner \& Bogner, 2009). One reason for this trend may be that students with learning disabilities are more likely to need additional support when processing information from multiple sources, particularly large blocks of texts. Studentfilled-in ViDis usually contain a predetermined structure with nodes and key concepts, providing students scaffolding through material design. Additionally, student-filled-in ViDis guide students to eliminate irrelevant information by presenting students with the overall structure of a concept or paragraph. Notably, findings from these studies are generally consistent for average readers and students with learning disabilities. Appendix B presented the findings from four 
experimental and quasi-experimental studies, demonstrating student-filled-in ViDis yield positive effects for instructing average readers and students with learning disabilities.

Furthermore, research has shown that through the use of student-filled-in ViDis, students with learning disabilities improved on different levels of learning (i.e., comprehension and application) in English Language Arts (e.g., Boulineau et al., 2004) and social studies (e.g., Ciullo et al., 2015). For instance, in two single-subject-design studies, two research groups (Ciullo et al., 2015; Ciullo, Falcomata, \& Vaughn, 2015) found upper elementary students gradually improved discrete content knowledge of social studies during visual literacy intervention. Whereas in an experimental study, DiCecco and Gleason (2002) revealed 6th-8th graders with learning disabilities performed better in application tasks rather than factual knowledge assessments after completing ViDis $(d=0.97 ; d=0.05$, respectively). In summary, these results, while promising, are not extensive and the learning types benefitting from studentfilled-in ViDis needs further exploration.

Student-created ViDis. The final category refers to visuals completely generated by students, named student-created ViDis. Compared with the aforementioned ViDis, studentcreated ViDis often require students to use higher-order cognitive skills and production tasks. For instance, upon reading a text, students need to extract information, justify, apply, and synthesize information they read, and finally create the ViDis on their own or with peers. Due to the task complexity, we found researchers showed more interest in investigating this issue with a focus on upper elementary and secondary students, likely assuming older students had already acquired basic literacy skills. Findings from the included studies were consistent, revealing students significantly improved their content-area learning when creating diagrams (e.g., Cromley et al., 2013a), concept maps (e.g., Kwon \& Cifuentes, 2009; Wang, Huang, \& Hwang, 
2016), mixed ViDis (i.e., graphs, pie charts, diagrams, Terwel et al., 2009), and pictures (i.e.,

Cohen \& Johnson, 2012; Schmeck et al., 2014). In summary, this intervention seems highly promising for promoting learning with upper elementary and older students (see Appendix B).

Regarding younger students, current research provided only limited insight regarding their learning processes and effects from fully creating ViDis. Only two studies focused on lower elementary levels (i.e., K-3, Cohen \& Johnson, 2011; Enyedy, 2005) and used distinctly different outcome measures for informational texts. Enyedy's (2005) qualitative study addressed the importance of activities. Specifically, second- and third-grade students improved their content learning through science informational texts by creating maps accompanied by activities, such as problem identification, group discussion, and collaboration. Students invented solutions and produced maps to solve problems. In contrast, Cohen and Johnson's (2011) experimental study focused on how visuals facilitate students' basic literacy skills by examining second-grade students' recall of science terminologies through a process of image creation. Findings indicated a significant difference between the image creation group and the text-only group. Therefore, these findings suggest a benefit for younger students, but with a small sample size, more research is needed to validate such a conclusion.

Notably, we provide a caution to these results: while having students create ViDis yielded substantial learning benefits, the process often requires a complex skillset. Thus, students are more likely to need additional support or instruction (e.g., scaffolding, instruction, and modeling) to integrate information and create ViDis (Authors, 2010; Kwon \& Cifuentes, 2009). Therefore, these findings do not recommend simply assigning such a task to students, but for teachers to follow an instructional sequence with graduate release supported through modeling and feedback. 
In summary, based on the interaction with ViDis, we classified ViDis into three categories: author-provided, student-filled-in, and student-created. Within author-provided, findings show that concrete visuals are effective only when these prompt students to organize and integrate information from multiple sources. However, unlike concrete ViDis, abstract visuals often require more effort to learn. Although researchers add additional elements (e.g., captions, arrows) to support students' processing, these elements yield inconsistent learning effects. In contrast, using ViDis with analogies, and using mixed types of ViDis showed promising results. Regarding student-filled in ViDis, findings indicate that students with learning disabilities benefited at different levels of learning. Furthermore, when students create ViDis, the intervention is highly promising for upper elementary and older students. However, becaue in most cases, researchers provided students with additional instruction or support, the findings need to be interpreted with caution.

Support for students' content-area learning. With the increasing visual complexity in K-12 curricula, research has shifted from investigating the simple effects of visuals on students' learning to examining the extent additional intervention or support promotes their learning. Therefore, we transition now to the activities surrounding ViDis categorized into three dimensions: content, strategy, and duration. In total, we found over half of the included studies provided students support before or during a ViDi intervention $(\mathrm{n}=59 \%)$.

Content. The focus of interest in a large body of exploration was directed toward literacy instruction, content-specific instruction, and visual convention instruction.

Instruction on basic literacy skills. Two research groups worked to promote students' learning by delivering instruction on literacy skills prior to using visual elements. Both studies focused on students with learning disabilities. For instance, in a single-subject design, Boulineau 
This is an author-produced, peer-reviewed version of this article. The final, definitive version of this document can be found online at Journal of Visual Literacy, published by Routledge. Copyright restrictions may apply. doi: 10.1080/1051144X.2019.1611702

THE IMPACT OF VISUAL DISPLAYS FOR LEARNING ACROSS DISCIPLINES

and colleagues (2004) taught fourth graders story grammar, such as setting, characters, and identifying connections among story components in narrative texts. Thus, students demonstrated skills related to recognizing story components before using a graphic organizer. As such, the story map served as a tool to record and organize previously taught information, which further facilitated students' reading comprehension.

Compared to Boulineau et al. (2004), in DiCecco and Gleason's (2002) study, teachers delivered instruction not only on reading comprehension strategies (e.g., inference) but also on vocabulary knowledge and decoding skills using informational texts. As middle school students are familiar with vocabulary and reading strategies, they are more likely to distribute energy on analyzing and processing information when using graphic organizers. Although findings from both studies showed the intervention yielded positive effects on students' learning, more studies are needed to directly investigate the effectiveness of providing literacy instruction before using graphic intervention, as in most cases, the literacy instruction accompanied other types of instructions (e.g., visual convention).

Visual convention instruction. Researchers also investigated instruction on visual convention, specifically for students using diagrams (i.e., Bergey et al., 2015; Cho \& Jonassen, 2012; Cromley et al., 2013b; Miller, Cromley, \& Newcomb, 2016; Swanson, 2015) and graphic organizers (e.g., Ciullo, Falcomata \& Vaughn, 2015). However, not all studies directly compared students who received visual convention instruction with students who only used ViDis. Frequently, visual convention instruction accompanied other interventions for both groups in the same study. Thus, it is difficult to generate a conclusion regarding the impact of visual convention instruction. For instance, working with 11th graders, Cho and Jonassen (2012) compared three interventions: instructional explanation, self-explanation, and meta-level 
feedback. Because students in all three conditions received instruction on visual convention (e.g., how to interpret diagrams in informational texts), we are unable to make any inferences regarding the pure effect of instruction on visual convention.

Only few experimental studies provided more insight regarding the effect of visual convention instruction (e.g., Bergey et al., 2015; Cromley et al., 2013b; Miller, Cromley, \& Newcomb, 2016; Swanson, 2015). For instance, in Cromley et al.'s (2013b) study, when teaching science informational texts, teachers provided diagram conventions tips to students in the experimental group, allowing them to understand declarative knowledge (e.g., how to interpret color keys in diagrams) and procedural knowledge (e.g., when to interpret a specific part in a diagram). Students then completed workbooks to practice those strategies. Unlike the experimental group, students in the control group occasionally received demonstrations of the diagrams' meaning, but no workbook was provided. In most cases, findings indicated that students who received instruction in the convention of diagrams presented greater growth in math ability (Swanson, 2015; Swanson, Lussier, \& Orosco, 2013) and diagram comprehension (Cromley et al., 2013b; Leopold et al., 2015; Miller, Cromley, \& Newcomb, 2016), and referential connection in biology (Leopold et al., 2015). Only one study (see Bergey, 2015) demonstrated that students in both groups showed significant but similar growth in comprehension.

Content-area specific instruction. Investigation of content-area instruction focused on three disciplines: mathematics, science, and safety education (e.g., Cromley et al., 2016; Kwon \& Cifuentes, 2009; Moreno, Ozugul, \& Reisslein, 2011; Sun \& Lee, 2016; Terwel et al., 2009). These studies focused on informational texts. Particularly, researchers using different instructional methods to teach content-specific concepts prior to using ViDis through 
experimental and quasi-experimental study designs. For instance, Cromley et al. (2016) used case comparisons to highlight key science concepts. Sun and Lee (2016) asked eighth- and ninthgrade students questions regarding concepts of anti-phishing and instructed them to poll and discuss answers after scanning the passage. Terwel et al. (2009) had fifth graders work in a creative manner by instructing them to connect math problems with real-life situations, then students recontextualized mathematical concepts and strategies in different contexts. In Moreno and colleagues' (2011) study, high-school students were instructed on the meaning of physics concepts followed by explicit examples showing principle application (e.g., Ohm's Law). Through instruction on the content area, students were more likely to understand the correlation of concepts and construct the mental framework. However, limited studies have directly examined the effect of content instruction, therefore, we are unable to conclude the effectiveness of content-area specific instruction.

Strategies/Activities. In the body of research on the impact of ViDis for K-12 students' content-area learning, we also found researchers designed a series of activities to guide students' use of graphic devices. In summary, these activities encompassed instructional feedback, peer collaboration, and metacognitive strategy.

Instructional feedback/guided practice. Multiple researchers considered teachers' instructional feedback as an important way to enhance students' content-area learning of informational texts when using ViDis within the instruction (e.g., Bergey et al., 2015; Cromley et al., 2013a; Swanson, 2015; Swanson, Lussier, \& Orosco, 2013). Specifically, teachers often asked probing questions (Bergey et al., 2015) or delivered instruction on the procedure, and/or content and visual convention knowledge (e.g., Swanson, 2015; Swanson, Lussier, \& Orosco, 2013). Then students worked on exercises to practice those strategies. Most importantly, teachers 
This is an author-produced, peer-reviewed version of this article. The final, definitive version of this document can be found online at Journal of Visual Literacy, published by Routledge. Copyright restrictions may apply. doi: 10.1080/1051144X.2019.1611702

provided feedback to clarify the confusion that students demonstrated in the exercise and correct misunderstandings to promote students' in-depth understanding. When provided with such feedback, students learned how to apply strategies. Finally, students used visuals and text to apply strategies in independent practice. Although multiple groups of researchers provided students instructional feedback, the impact of such instruction has not fully explored.

Peer collaboration. Another way to promote students' learning with visuals is through peer collaboration. Convergent findings from both qualitative and quantitative studies, addressed the positive effects when students work in pairs or groups to complete visual graphic tasks (e.g., Áberg-Bengtsson, 2006; Enyedy, 2005; Gerstner \& Bogner; 2009; Sun \& Lee, 2016). We only identified one quasi-experimental study (see Kwon and Cifuentes, 2006), in which researchers directly compared the effects of individually constructing visuals with that of collaboratively creating visuals. Specifically, Kwon and Cifuentes (2006) instructed seventh-grade students to work collaboratively, allowing them to improve their knowledge construction in science.

Findings show the peer collaboration group outperformed students who worked individually on creating higher quality concept maps, indicating in-depth conceptual understanding $(d=0.91)$. The positive finding may be due to the fact that peer collaboration allowed students to share and discuss the representations of their mental structures in an interactive manner.

Self-explaining and meta-cognitive strategy. For students who worked individually to complete visual tasks, teachers supported their content-area learning by teaching them metacognitive strategies, such as self-explaining (e.g., Berthold \& Renkl, 2009; Cho \& Jonassen, 2012; Cromley et al., 2013a). Self-explaining refers to "an activity that students make sense of new information either presented in a text or in some other medium', (Chi, 2000, p. 164). This strategy allows students to interpret and understand new information presented in text and 
This is an author-produced, peer-reviewed version of this article. The final, definitive version of this document can be found online at Journal of Visual Literacy, published by Routledge. Copyright restrictions may apply. doi: 10.1080/1051144X.2019.1611702

visuals, make inferences, as well as monitor their reading process. For instance, Cromley and colleagues (2013a) provided high-school students questions to prompt the use of self-explanation strategy during reading. Students actively extracted meanings and made inferences from reading via self-explanation. Findings demonstrated that the self-explanation method showed positive impacts on high-school students' knowledge construction and diagram comprehension of informational texts (see Appendix B).

However, as Berthold and Renkl (2009) revealed, when compared with younger students, older students may generate incorrect interpretation based on their prior knowledge or false impressions. As such, the self-explanation effect may be reduced by misunderstandings. Thus, to reduce the limitations of self-explanation, researchers (Berthhold \& Renkl, 2009; Cho \& Jonassen, 2012) also instructed students to use meta-level feedback with self-explaining. Metalevel feedback is an effective strategy that allows students to compare their self-explanation responses with instructional explanations, which teachers previously taught, and reflect on their explanations of text and ViDis. Such feedback proves particularly beneficial for students who generated incorrect responses based on their prior knowledge. Findings demonstrate that upper middle school students in the meta-level feedback condition outperformed students in instructional explanation condition on recall and inference tasks. However, interestingly, it did not show a significant difference between the meta-level feedback group and the self-explanation group (Cho \& Jonassen, 2012).

Researchers' explanations. Another related strategy to promote students' learning includes adding researchers' explanation to facilitate learners' understanding of multimodal texts. However, we only identified one experimental study that added researchers' oral explanation to accompany visuals and text to promote students' learning of informational texts 
This is an author-produced, peer-reviewed version of this article. The final, definitive version of this document can be found online at Journal of Visual Literacy, published by Routledge. Copyright restrictions may apply. doi: 10.1080/1051144X.2019.1611702

THE IMPACT OF VISUAL DISPLAYS FOR LEARNING ACROSS DISCIPLINES

(see Segers et al., 2008). Specifically, researchers found when presenting fifth-grade students with both oral and graphic presentations, students with varying verbal abilities produced better short-term performance (Segers et al., 2008).

Although research methods vary, these studies sought to develop a deeper understanding of how to promote K-12 students' learning from multimodal texts across disciplines using activities or interventions in a more effective manner. To conclude, using activities or interventions provides a useful direction for future research, but we need more studies to compare the strength of different interventions (e.g., instructional feedback versus peer collaboration) to clarify when and how these interventions are effective. Furthermore, we need more qualitative studies to investigate the learning process, especially how students use these strategies to improve learning.

Duration. Notably, these interventions also varied in duration. Some researchers provided students short-term intensive instruction (e.g., Áberg-Bengtsson, 2006; Moreno, Ozugul, \& Reisslein, 2011), whereas others promoted students' learning in a more comprehensive way, aiming to enhance the learning through long-term intervention (e.g., Cromley et al., 2013a; Swanson, 2015).

Short-term intensive instruction. Short-term instruction usually occurred before the formal intervention, aiming to provide general procedural knowledge for students. This step can be important for students who are unfamiliar with experiment procedure or lacking experience working in multimedia environments (e.g., Áberg-Bengtsson, 2006; Moreno, Ozugul, \& Reisslein, 2011). For instance, in Moreno, Ozugul and Reisslein's (2011) study, tutors delivered only one lesson to high-school students on procedural knowledge. After students learned several electrical circuit diagrams, they completed practice problems online and completed a paper-and- 
This is an author-produced, peer-reviewed version of this article. The final, definitive version of this document can be found online at Journal of Visual Literacy, published by Routledge. Copyright restrictions may apply. doi: 10.1080/1051144X.2019.1611702

THE IMPACT OF VISUAL DISPLAYS FOR LEARNING ACROSS DISCIPLINES

pencil transfer test. Although students in three groups received different instructions (e.g., how to read concrete diagrams, abstract diagrams, or both), teachers provided short-term instruction for all groups. Therefore, we are unable to compare the impacts of short-term instruction with longterm intervention.

Long-term intervention. Compared with short-term instruction, long-term intervention varied in format, but in general, teachers presented rigorous lessons as related to content with visuals embedded within the instructional sequence. Usually, teachers delivered instruction step by step in each lesson, and repeated the same procedure in the next session (e.g., Bergey et al., 2015; Cromley, 2016; Cromley et al., 2013a; Miller et al., 2016; Swanson, 2015). For instance, working with second graders, teachers delivered 20 lessons over eight weeks on calculation of mathematical problems using verbal, visual, or both verbal and visual strategies (see Swanson, 2015). The comprehensive instruction included a warm-up, instructional intervention, guided practice, and independent practice. Teachers taught students in the visual strategy group how to use diagrams to solve problems. Similarly, Cromley and colleagues (2013a) also provided upper middle school students multiple lessons on science topics over a six-week period. In each lesson, teachers first delivered instruction, and then students worked in groups to complete worksheets, with scaffolding from the teacher. The teacher provided feedback on students' answers, explaining the incorrect items.

We only identified one experimental study that reported the effects of a 4-week, and a 10week intervention (see Miller, Cromley, \& Newcomb, 2016). Researchers found 10-week instruction on visual conventions significantly enhanced 8th graders' diagrammatic reasoning and comprehension of science content, compared to the control group $(d=0.47, d=0.41)$. However, when the intervention duration reduced to 4 weeks, no significant difference was 
This is an author-produced, peer-reviewed version of this article. The final, definitive version of this document can be found online at Journal of Visual Literacy, published by Routledge. Copyright restrictions may apply. doi: 10.1080/1051144X.2019.1611702

THE IMPACT OF VISUAL DISPLAYS FOR LEARNING ACROSS DISCIPLINES

found between groups $(d=-0.10, d=-0.2)$. In summary, long-term intervention allows students more time to process the information they learned in the previous lesson. Therefore, through repeated instruction, students strengthen knowledge on visual convention, reading strategies, and content knowledge.

To conclude, we synthesized the reviewed studies, and generated three themes regarding the support for students' content-area learning: content, strategies/activities, and duration. Within the first theme, findings show providing literacy instruction, as well as visual convention instruction, is effective for facilitating classroom use of student-created visual displays. However, as research has not fully examined the effect of content-area specific instruction, it is difficult to generate a conclusion. Within the second theme, researchers investigated the effectiveness of strategies/activities, including instructional feedback, guided practice, peer collaboration, self-explaining, meta-cognitive strategy, and researchers' explanation. In general, these activities promote students' learning from ViDis, however, due to the small sample, more studies are needed to validate the conclusion. In terms of intervention duration, we only found one study that examined the effectiveness of long-term and short-term intervention. As anticipated, findings demonstrated that through repeated longer-term instruction, students gained a better learning outcome.

Types of Knowledge and Learning. According to Mayer (2001), ViDis usually promote higher-level learning, such as problem-solving, rather than recall. These findings are consistent for students; however, this information provides little insight when we attempt to translate Mayer's principles to younger readers. Therefore, through a systematic review of research on K12 students, the following section focuses on different levels of learning outcomes across disciplines. Specifically, we borrowed the revised Bloom's taxonomy (Anderson, Krathwohl, \& 
Bloom, 2001) to summarize the impact of ViDis on students' cognitive learning.

Remembering. We found three studies measuring students' vocabulary retention in stories or informational texts (i.e., Acha, 2009; Cohen \& Johnson, 2011; 2012). Interestingly, all studies centered on younger students (e.g., kindergarten and elementary students). Specifically, Cohen and Johnson $(2011,2012)$ considered elementary native speakers' memorization and retention of science vocabulary after imagery interventions, whereas Acha (2009) focused on English Language Learners (ELLs). Findings indicated that when compared with students in the text-only condition, using ViDis significantly improved native speakers' vocabulary recall (Cohen \& Johnson, 2011; 2012). However, using ViDis did not show positive impacts on ELL students' vocabulary retention (Acha, 2009).

Moreover, the effects are mixed when researchers measured students' retention of factual content knowledge and main ideas of informational texts across disciplines (e.g., DiCecco \& Gleason, 2002; Mason, Tornatora, \& Pluchino, 2013; Zheng et al., 2008). The mixed effect may be due to various factors, such as treatment effect, and the extent students are capable of integrating text and ViDis. For instance, DiCecco and Gleason (2002) and McTigue (2009) found no differences between treatment (e.g., using ViDis and text) and control condition (e.g., using text only) in factual knowledge retention tasks. However, Cho and Jonassen (2012) found that when 11 th graders are able to use meta-level feedback during reading, they outperformed students who use other strategies (e.g., instructional explanation or self-explanation) on recall and inference tasks. Similarly, Zheng et al. (2008) revealed when using multimedia with an analogy, fourth-graders demonstrated the highest performance on retention of factual and procedural knowledge among all groups. Therefore, we may conclude that simply using visuals may prompt students' vocabulary recall but may not directly improve students' knowledge 
recall.

Understanding. A large proportion of studies $(n=23)$ focused on the impact of ViDis on students' reading comprehension (e.g., Boulineau et al., 2004; Cromley, 2013a, 2013b). Specifically, these studies measured when, how, and why ViDis could promote elementary and secondary students' literal and inferential comprehension. However, findings regarding the effect of ViDis on reading comprehension are inconsistent, as we found 17 studies found positive effects (e.g., Berthold \& Renkl, 2009; Segers et al., 2008), and six reported no effects (e.g., Author, 2009; Norman, 2012). As previously mentioned, the mixed effect may be attributed to many factors, such as intervention features and graphic designs. For instance, in multiple cases, students received instruction on procedural knowledge and content-specific skills, which allowed them to apply various strategies to integrate information from multiple sources (e.g., Cho \& Jonassen, 2012; Cromley, 2013b), whereas others attempted to facilitate students' understanding through graphic design (e.g., Author, 2009).

Furthermore, students' characteristics are another important factor that moderates the impact of visuals, such as their prior knowledge, attention, and reading skills. Data collected via the think-aloud method and eye-tracking technique may provide an in-depth understanding of this complexity. According to Jian (2017), compared with less-skilled readers, skilled readers spent significantly more effort and time on both text and ViDis and attempted to process the article holistically. Moreover, skilled readers are more likely to integrate the corresponding information from multiple sources during reading.

Another factor accounting for the mixed effect may be assessment format. Reading comprehension can be measured through different tasks: cloze, short answer questions, multiplechoice questions, true/false, or drawing. For instance, to measure eighth-grade students' 
This is an author-produced, peer-reviewed version of this article. The final, definitive version of this document can be found online at Journal of Visual Literacy, published by Routledge. Copyright restrictions may apply. doi: 10.1080/1051144X.2019.1611702

THE IMPACT OF VISUAL DISPLAYS FOR LEARNING ACROSS DISCIPLINES

conceptual information comprehension, Schmeck et al. (2014) had students draw the main ideas given in the science text. Whereas in most cases (e.g., Authors, 2009, Cromly et al., 2013b), reading comprehension was measured through standardized tests (i.e., multiple-choice format). Although researchers attempted to measure students' comprehension, tasks such as short answer and drawing are likely to involve more cognitive demand than true/false or multiple-choice questions. However, to validate this conclusion, an increasing call for future research to test students' reading comprehension via different measurement forms exists.

Applying, Analyzing, and Evaluating. Although Anderson and colleagues (2001) distinguished three levels of learning (i.e., applying, analyzing, and evaluating), in the field of ViDis, we found researchers often measure various learning levels through a single assessment. For instance, when handling a mathematical problem, students need to analyze information and evaluate information accuracy, then integrate relevant information from multiple sources, and finally transfer knowledge and apply it to solve the problem. Therefore, we discuss these three skills together in this section.

Interestingly, we found that researchers frequently use ViDis to promote students' analysis, evaluation, and application of knowledge and principles in STEM education, such as mathematics (e.g., Elia, Gagatsis, \& Demetriou, 2007; Pyke, 2003) and science (Leopold et al., 2015; Segers et al., 2008). In most cases, the effects are positive. For instance, Van Garden (2007) conducted an experiment on sixth-grade students, revealing a positive correlation between the use of visuals and better performance on mathematical problem-solving tasks. However, according to Elia, Gagatsis, and Demetriou (2007), this effect may be moderated by students' age and graphic design. In a study, they analyzed 1447 first-, second-, and third-grade students' performance in a large-scale math assessment through structural equation modeling. The results 
This is an author-produced, peer-reviewed version of this article. The final, definitive version of this document can be found online at Journal of Visual Literacy, published by Routledge. Copyright restrictions may apply. doi: 10.1080/1051144X.2019.1611702

THE IMPACT OF VISUAL DISPLAYS FOR LEARNING ACROSS DISCIPLINES

indicated the representation type (decorative, informational, number line) moderated students' mathematical problem-solving performance. However, research revealed the way students handle representations changes with age. Moreover, when compared with decorative ViDis, informational pictures may hinder younger students' problem-solving abilities, as they may require more complex mental processes. Notably, we only identify one study using large-scale assessment, therefore the findings should be interpreted with caution.

Demonstrating Learning through Creating. Creation is considered as the most complex task in revised Bloom's taxonomy (Anderson, Krathwohl, \& Bloom, 2001). In the reviewed studies, creation was not an outcome measure but described how students interacted with ViDis. However, to align Bloom's taxonomy with the current study, we felt it essential to consider creation as a learning focus. We found in most cases, students created ViDis on their own or with peers, often for the purpose of problem-solving. Findings on creation were consistent in general, indicating that using ViDis enhanced students' learning (e.g, Moreno, Ozugul, \& Reisslein, 2011; Terwel et al., 2009). For instance, Terwel et al. (2009) investigated the effectiveness of different visual types on problem-solving. They compared the control group who learned how to use researcher-provided visuals to the experimental group who learned to design and use visuals as a tool to solve problems. Findings show that the experimental group outperformed the control group in the post-assessment, indicating a better understanding of ViDis could facilitate students' higher-level learning skills, such as problem-solving through creating. However, notably in many cases teachers frequently instructed students with a series of scaffolding activities on content and visual conventions prior to measuring the learning outcomes. Through these activities, students were able to acquire corresponding skills and apply strategies to solve problems. As a result, creating ViDis may yield large learning benefits. 
In summary, the effect of ViDis are mixed when researchers examine the impact of ViDis on students' recall and comprehension of information. Furthermore, findings on higher-order learning outcomes were generally consistent, demonstrating that students benefit from using ViDis on evaluation and application of knowledge and principles in STEM education. However, these positive effects may be moderated by students' age and graphic design (Elia, Gagatsis, and Demetriou; 2007). Regarding creation, multiple groups of researchers found creating ViDis may yield large learning benefits. Notably, students are often provided with instruction prior to completing the task. Therefore, the findings need to be interpreted with caution.

\section{Central Findings on How ViDis Support Content-Area Learning: Consideration of}

\section{Best Practices for Teachers}

Based on the analysis of the themes explicated above and synthesis of our research questions, we distilled findings into the following evidence-based recommendations. Our goal is to inform teachers' agentive instructional decision-making based on content and student need, through an evidence-based lens. Synthesizing results from this literature review assist us in informing teacher practice. In that vein, we endorse inclusion of best practices noted below.

For these endorsements, we focus on research question three, In what ways does the incorporation of visual graphic tasks (e.g., content, strategies, and duration) benefit students' various types of learning?. We recognize that embedded within question three are the conditions which enhance student learning. The duration and selection of visual graphic tasks impact student learning. We cogently endorse recommendations based on the conditions of question two, Under what conditions do ViDis enhance students' learning?. These questions proved valuable to situate our considerations of best practices for classroom visual graphic integration.

\section{Incorporation of ViDi Tasks to Enhance Student Learning}


Author-provided ViDis. Author-provided ViDis includes both concrete and abstract

ViDis. Not surprisingly, concrete ViDis (e.g., photographs) are not very effective for enhancing students' learning when they are either decorative in function or simply present information in the text (e.g., Acha, 2009). Therefore, when selecting concrete ViDis or texts, teachers should consider the conceptual alignment of text and ViDis. Only when students are able to integrate information from both sources (ViDis and text), can using ViDis yield positive effects (Jian, 2017). In situations when the ViDis and texts are not well aligned, in the manner of critical literacy, we recommend teachers draw students' attention to this discrepancy and help them focus on pertinent information.

In terms of abstract ViDis (e.g., flow diagram), the abstract nature of this format may require more effort to comprehend (Authors, 2017). Findings from the reviewed studies show that researchers worked to promote students' learning through additional elements (e.g., using materials with analogies, using mixed types of ViDis). More importantly, students may benefit from teachers providing scaffolding through multiple support methods, such as modelling, having students engage in self-explanation of content, providing meta-level feedback (Berthold \& Renkl, 2009; Cho \& Jonassen, 2012; Cromley et al., 2013a), and teaching visual conventions to facilitate students' learning skills to extract and organize information from different sources (Cromley et al., 2013b; Cromley et al., 2016).

Student-constructed ViDis. Student-constructed ViDis usually involved a more active learning process. Further, based on the level of interaction with ViDis, we distinguished studentfilled-in (e.g., graphic organizer) and student-created ViDis (see below for further discussion). Student-filled-in ViDis usually require students to seek and integrate information from the text and connect new content with an existing schema. They proved particularly powerful for 
students with learning disabilities, although with teacher support. These ViDis allow teachers a mechanism to scaffold their instruction (e.g., Boulieau et al., 2004; Ciullo et al., 2015).

Additionally, our synthesis indicates student-created ViDis (e.g., draw a diagram of a heart) are highly promising for promoting learning with upper elementary and secondary students, as they often involve higher-order learning skills (e.g., evaluate information in a diagram and transfer knowledge to solve problems). This result may be explained as upper elementary and secondary students likely possessed the fundamental reading skills acquired in early grades, freeing their mental capacity for handling more complex tasks. However, it is also important to note that in many cases teachers modeled and provided short- or long-term contentarea specific instruction (e.g., Moreno, Ozugul, \& Reisslein, 2011; Sun \& Lee, 2016). Therefore, when students are able to use and apply the corresponding skills necessary for the task, creating ViDis yielded large learning benefits.

\section{Conditions for Enhanced Student Learning}

Regarding types of knowledge and learning, we found ViDis promoted younger native speakers' vocabulary recall (e.g., Cohen \& Johnson, 2011; 2012). An association between vocabulary and imagery/concreteness has been previously explored by Sadoski and colleagues (2003) in which they found a relationship between participants' quality of word definitions and concreteness. Therefore, we encourage teachers to consider capitalizing on concrete visuals when teaching native speakers vocabularies. In practice, this task may be accomplished by providing students with visual cues for each word or having students create their own cues (Sadoski, Goetz, Stricker, \& Burdenski, 2003) as a means to access available learning pathways. However, for English Language Learners, teachers need to consider their additional language demands to enlarge the positive effects of ViDis. 
This is an author-produced, peer-reviewed version of this article. The final, definitive version of this document can be found online at Journal of Visual Literacy, published by Routledge. Copyright restrictions may apply. doi: 10.1080/1051144X.2019.1611702

THE IMPACT OF VISUAL DISPLAYS FOR LEARNING ACROSS DISCIPLINES

Although findings suggest a positive effect of ViDis on K-12 students' higher learning (e.g., Terwel et al, 2009; Swanson, Lussier, \& Orosco, 2013), we cannot assume that simply using ViDis will lead to higher-order learning. Therefore, we suggest teachers design a series of activities to promote higher-order learning via ViDis, rather than simply having students read multimodal texts. For instance, teachers could provide feedback on student-created ViDis, have students explain the steps of using visuals to solve math problems, pair up students to compare different parts in a science diagram, and design project-based activities to connect the abstract terms with students' life experiences (Enyedy, 2005). Our suggestions for teachers represent our positioning of educators as advocates in the process of visual graphic integration and implementation. Teachers' contextual knowledge situates them as the best equipped to enact instructional supports with ViDis to enhance content-area learning.

\section{Limitations}

As this study used the systematic literature review procedure as the methodology, it has several inherent limitations. First, our rigorous screening process limited the number of included studies, thus narrowing the review's scope. However, using a methodological screener allowed us to have greater confidence in the findings. Second, despite the methodological screening, many researchers used only a single assessment to measure various learning levels. Therefore, the interaction with different learning types and ViDis cannot be fully explored. Although we employed MQIs to evaluate the quality of review studies, some quantitative studies involved small sample sizes, which may lead to insufficient power to extrapolate statistical analysis, raising further concerns of unreliable findings. Furthermore, our sample underrepresented certain learner groups, particularly English Language Learners (ELLs), since we only identified one study mainly focused on this population. Therefore, findings from this research synthesis should 
This is an author-produced, peer-reviewed version of this article. The final, definitive version of this document can be found online at Journal of Visual Literacy, published by Routledge. Copyright restrictions may apply. doi: 10.1080/1051144X.2019.1611702

THE IMPACT OF VISUAL DISPLAYS FOR LEARNING ACROSS DISCIPLINES

be applied to native language speakers in K-12 context.

\section{Recommendations for Future Research}

For whom. The research on how different learner types interact with ViDis remains scarce. For example, regarding ELLs, we only identified one study exploring the visual facilitation for ELLs. Although the existing literature frequently demonstrated the importance of visual strategies to improve ELLs' reading comprehension (Watkins \& Lindahl, 2010), limited empirical studies were conducted with this population. Moreover, because multimodal text in lower elementary textbooks becomes increasingly complex, a need exists to decide when and how to integrate ViDis with younger readers. Renkl and Scheiter (2017) identified a similar need regarding the interaction of ViDis with the prior knowledge levels of learners, and Authors (2009) with learning from graphics and age.

How. The research topics regarding ViDis have shifted from investigation on graphic design to exploration of instruction for K-12 students. In general, these studies provide in-depth insight regarding the effects of teachers' explanatory instruction. However, limited studies focus on specific strategies, especially how students use explanatory and metacognitive strategies during reading and when these strategies promote students' learning. For instance, Berthold and Renkl (2009) compared three reading strategies (e.g., explanatory instruction, self-explain strategy, and meta-level feedback), revealing ViDis are most effective when students are able to use self-explain and meta-level feedback together. Therefore, more studies are needed to replicate these principles and examine instrument validity. Moreover, multiple groups of researchers provided student content-area specific instruction prior to use ViDis, however, limited research explored the effectiveness of content-area specific instruction. More future studies are needed on this topic. Finally, when designing instructional activities, researchers 
should consider students' prior knowledge, procedural knowledge, visual convention, and content-specific knowledge. Therefore, it is important for future endeavors to further investigate these factors and provide more support for younger students.

Assessment type. When examining 88 articles with the methodological quality indicators, we found a majority of quantitative studies used standardized tests to measure different learning levels. However, in many cases, researchers did not report the measures' reliability or validity. We aim to highlight the importance of instrument reliability, as it could directly moderate the findings. For instance, in a previous study, when researchers used three comprehension assessments to identify struggling readers, they found using three standardized tests could yield very different results (Rimrodt, Lightman, Roberts, Denckla, \& Cutting, 2005). Therefore, we encourage researchers to develop and use reliable measurements (or at minimum report reliability statistics) when assessing students' learning. Moreover, a majority of the studies used quantitative methods, with only six reporting mixed-method designs. Therefore, more expansive studies are needed that collect data from multiple sources and provide insight regarding students' learning processes across disciplines.

\section{Conclusion}

In this review, we addressed the complexity of incorporating ViDis with content-area and disciplinary learning, providing future endeavors with a foundational understanding of the research trends and findings in visual graphic research. Through a systematic review of empirical studies, this study aimed to answer: In what ways does the incorporation of visual graphic tasks benefit K-12 students' content-area learning?. Based on the interaction with ViDis, we first distinguished three types of ViDis (a) author-provided, (b) student-filled-in, and (c) studentcreated. Through a comprehensive evaluation of these ViDis, we discussed their effectiveness on 
This is an author-produced, peer-reviewed version of this article. The final, definitive version of this document can be found online at Journal of Visual Literacy, published by Routledge. Copyright restrictions may apply. doi: 10.1080/1051144X.2019.1611702

THE IMPACT OF VISUAL DISPLAYS FOR LEARNING ACROSS DISCIPLINES

students' learning across disciplines. We also analyzed data collected via the think-aloud method and eye-tracking techniques aiming to provide an in-depth understanding of these complex procedures. In summary, we found that simply using ViDis does not guarantee a positive learning effect. To promote students' learning, teachers must take on an agentive role and guide students' information integration across texts.

Furthermore, we evaluated the intervention from previous research on ViDis and contentarea learning, resulting in analyses guided by three categories: content, strategies, and duration. Regarding content, teachers often provide literacy instruction, content-specific instruction, and visual convention instruction. In general, we found students benefit from literacy and contentspecific instruction, especially when teaching mathematics and science. However, not all studies directly compared students who received visual convention instruction with those students who only used ViDis. Thus, it is difficult to generate a conclusion regarding the impact of visual convention instruction. Finally, we analyzed types of knowledge and learning and found visuals consistently promoted native speakers' vocabulary recall. However, visuals did not consistently promote gains in content knowledge. Most promising, consistent with previous research (e.g., Mayer, 1989; Mayer \& Gallini, 1990), we found a general positive effect of ViDis on K-12 students' higher-order skills (e.g., problem-solving). Focusing on student-constructed ViDis often involved application of higher-order cognitive skills (e.g., applying, analyzing, and evaluating). Therefore, we argue student-constructed ViDis are beneficial for upper elementary and secondary students in conjunction with teacher provided instruction and support.

\section{References}

Authors, 2009; 2010; 2011; 2013; 2017; 2018; 2019 were removed for blind review. Samples 
This is an author-produced, peer-reviewed version of this article. The final, definitive version of this document can be found online at Journal of Visual Literacy, published by Routledge. Copyright restrictions may apply. doi: 10.1080/1051144X.2019.1611702

THE IMPACT OF VISUAL DISPLAYS FOR LEARNING ACROSS DISCIPLINES

included in the present study indicated by an asterisk (*).

*Åberg-Bengtsson, L. (2006). “Then you can take half... almost”-Elementary students learning bar graphs and pie charts in a computer-based context. The Journal of Mathematical Behavior, 25, 116-135. doi:10.1016/j.jmathb.2006.02.007

*Acha, J. (2009). The effectiveness of multimedia programmes in children's vocabulary learning. British Journal of Educational Technology, 40, 23-31. doi:10.1111/j.14678535.2007.00800.x

Anderson, L. W., Krathwohl, D. R., \& Bloom, B. S. (2001). A taxonomy for learning, teaching, and assessing: A revision of Bloom's taxonomy of educational objectives. New York, NY: Longman.

*Arya, P., \& Feathers, K. M. (2012). Reconsidering children's readings: Insights into the reading process. Reading Psychology, 33, 301-322. doi: 10.1080/02702711.2010.518881.

*Bergey, B. W., Cromley, J. G., Kirchgessner, M. L., \& Newcombe, N. S. (2015). Using diagrams versus text for spaced restudy: Effects on learning in 10th grade biology classes. British Journal of Educational Psychology, 85, 59-74. doi: 10.1111/bjep.12062

Bertin, J. (1983). Semiology of graphics: Diagrams, networks, maps (2nd ed.). Madison, WI: University of Wisconsin Press.

*Berthold, K., \& Renkl, A. (2009). Instructional aids to support a conceptual understanding of multiple representations. Journal of Educational Psychology, 101, 70-87. doi: $10.1037 / \mathrm{a} 0013247$

Britt, M. A., \& Gabrys, G. L. (2001). Teaching advanced literacy skills for the world wide web. 
In C. Wolfe (Ed.), Learning and teaching on the world wide web (pp. 73-90). Cambridge, MA: Academic Press.

Bloom, B.S. (Ed.). Engelhart, M.D., Furst, E.J., Hill, W.H., Krathwohl, D.R. (1956). Taxonomy of educational objectives. Handbook I: The cognitive domain. New York, NY: David McKay Co Inc.

*Boulineau, T., Fore Iii, C., Hagan-Burke, S., \& Burke, M. D. (2004). Use of story-mapping to increase the story-grammar text comprehension of elementary students with learning disabilities. Learning Disability Quarterly, 27, 105-121. doi: 10.2307/1593645

Brookshire, J., Scharff, L. F., \& Moses, L. E. (2002). The influence of illustrations on children's book preferences and comprehension. Reading Psychology, 23, 323-339. $10.1080 / 713775287$

Carney, R. N., \& Levin, J.R. (2002). Pictorial illustrations still improve students' learning from text. Educational Psychology Review, 14, 5-26. doi:10.1023/A:1013176309260

*Ciullo, S., Falcomata, T. S., Pfannenstiel, K., \& Billingsley, G. (2015). Improving learning with science and social studies text using computer-based concept maps for students with disabilities. Behavior Modification, 39, 117-135. doi: 10.1177/0145445514552890

*Ciullo, S., Falcomata, T., \& Vaughn, S. (2015). Teaching social studies to upper elementary students with learning disabilities: Graphic organizers and explicit instruction. Learning Disability Quarterly, 38, 15-26. doi: 10.1177/0731948713516767

*Cho, Y. H., \& Jonassen, D. H. (2012). Learning by self-explaining causal diagrams in highschool biology. Asia Pacific Education Review, 13, 171-184. doi: 10.1007/s12564-011- 
This is an author-produced, peer-reviewed version of this article. The final, definitive version of this document can be found online at Journal of Visual Literacy, published by Routledge. Copyright restrictions may apply. doi: 10.1080/1051144X.2019.1611702

THE IMPACT OF VISUAL DISPLAYS FOR LEARNING ACROSS DISCIPLINES

$9187-4$

Clark, J. M., \& Paivio, A. (1991). Dual coding theory and education. Educational Psychology Review, 3, 149-210. doi: 10.1007/BF01320076

*Cohen, M. T., \& Johnson, H. L. (2011). Improving the acquisition of novel vocabulary through the use of imagery interventions. Early Childhood Education Journal, 38, 357-366. doi: $10.1007 / \mathrm{s} 10643-010-0408-y$

*Cohen, M. T., \& Johnson, H. L. (2012). Improving the acquisition and retention of science material by fifth grade students through the use of imagery interventions. Instructional Science, 40, 925-955. doi: 0.1007/s11251-011-9197-y

Common Core State Standards. English Language Arts - Literacy (2009). Retrieved from http://www.corestandards.org/ELA-Literacy/RI/4/

Texas Education Agency. Texas Essential Knowledge and Skills for Science (2017). Retrieved from http://ritter.tea.state.tx.us/rules/tac/chapter112/

Cooper, H. M. (1982). Scientific guidelines for conducting integrative research reviews. Review of Educational Research, 52, 291-302.

*Cromley, J. G., Bergey, B. W., Fitzhugh, S. L., Newcombe, N., Wills, T. W., Shipley, T. F., \& Tanaka, J. C. (2013). Effectiveness of student-constructed diagrams and self-explanation instruction. Learning and Instruction, 26, 45-58.

*Cromley, J. G., Perez, T. C., Fitzhugh, S. L., Newcombe, N. S., Wills, T. W., \& Tanaka, J. C. (2013). Improving students' diagram comprehension with classroom instruction. The Journal of Experimental Education, 81, 511-537. doi: 10.1080/00220973.2012.745465 
*Cromley, J. G., Weisberg, S. M., Dai, T., Newcombe, N. S., Schunn, C. D., Massey, C., \& Merlino, F. J. (2016). Improving middle school science learning using diagrammatic reasoning. Science Education, 100, 1184-1213. doi: 10.1002/sce.21241

*DiCecco, V. M., \& Gleason, M. M. (2002). Using graphic organizers to attain relational knowledge from expository text. Journal of Learning Disabilities, 35, 306-320.

Duke, N. K., \& Bennett-Armistead, V. S. (2003). Reading and writing informational text in the primary grades: Research based practices. New York, NY: Scholastic.

*Elia, I., Gagatsis, A., \& Demetriou, A. (2007). The effects of different modes of representation on the solution of one-step additive problems. Learning and Instruction, 17, 658-672. doi: 10.1016/j.learninstruc.2007.09.011

*Enyedy, N. (2005). Inventing mapping: Creating cultural forms to solve collective problems. Cognition and Instruction, 23, 427-466. doi: 10.1207/s1532690xci2304_1

Fingeret, L. (2012). Visuals in children's informational texts: A content analysis. (Unpublished doctoral dissertation). Michigan State University, East Lansing, MI.

Hunter, B., Crismore, A., \& Pearson, P. D. (1997). Visual displays in basal readers and social studies textbooks. In H. A. Houghton \& D. M. Willows (Ed.), The psychology of illustration (pp. 116-135). Harrisonburg, VA: R. R. Donnelly \& Sons.

*Gerstner, S., \& Bogner, F. X. (2009). Concept map structure, gender and teaching methods: An investigation of students' science learning. Educational Research, 51, 425-438. doi: $10.1080 / 00131880903354758$

Gatto, J. A., Porter, A. W., \& Selleck, J. (2011). Exploring visual design: The elements and 
principles $\left(4^{\text {th }}\right.$ ed.). Worcester, MA: Davis Publications

Hannus, M., \& Hyönä, J. (1999). Utilization of illustrations during learning of science textbook passages among low-and high-ability children. Contemporary Educational Psychology, 24, 95-123.

*Jian, Y. C. (2017). Eye-movement patterns and reader characteristics of students with good and poor performance when reading scientific text with diagrams. Reading and Writing, 30, 1447-1472. doi: 10.1007/s11145-017-9732-6

Kress, G. and Van Leeuwen, T. (1996) Reading images: The grammar of visual design. London: Routledge.

Kulhavy, R. W., Stock, W. A., \& Caterino, L. C. (1994). Reference maps as a framework for remembering text. In Schnotz, W., \& Kulhavy, R. W. (Ed.), Comprehension of graphics (pp. 153-162). New York, NY: Elsevier Science.

Kulhavy, R. W., Stock, W. A., Woodard, K. A., \& Haygood, R. C. (1993b). Comparing elaboration and dual coding theories: The case of maps and text. Contemporary Educational Psychology. 106, 483-498.

*Kwon, S. Y., \& Cifuentes, L. (2009). The comparative effect of individually-constructed vs. collaboratively-constructed computer-based concept maps. Computers \& Education, 52, $365-375$.

*Lenzner, A., Schnotz, W., \& Müller, A. (2013). The role of decorative pictures in learning. Instructional Science, 41, 811-831. doi:10.1007/s11251-012-9256-z

*Leopold, C., Doerner, M., Leutner, D., \& Dutke, S. (2015). Effects of strategy instructions on 
learning from text and pictures. Instructional Science, 43, 345-364. doi: 10.1007/s11251014-9336-3

Levie, W. H., \& Lentz, R. (1982). Effects of text illustrations: A review of research. Educational Communication and Technology, 30, 195-232.

*Mason, L., Baldi, R., Di Ronco, S., Scrimin, S., Danielson, R. W., \& Sinatra, G. M. (2017). Textual and graphical refutations: Effects on conceptual change learning. Contemporary Educational Psychology, 49, 275-288. doi: 10.1016/j.cedpsych.2017.03.007

*Mason, L., Pluchino, P., Tornatora, M. C., \& Ariasi, N. (2013). An eye-tracking study of learning from science text with concrete and abstract illustrations. The Journal of Experimental Education, 81, 356-384. doi: 10.1080/00220973.2012.727885

*Mason, L., Tornatora, M. C., \& Pluchino, P. (2013). Do fourth graders integrate text and picture in processing and learning from an illustrated science text? Evidence from eye-movement patterns. Computers \& Education, 60, 95-109. doi: 10.1016/j.compedu.2012.07.011

*Marley, S. C., \& Szabo, Z. (2010). Improving children's listening comprehension with a manipulation strategy. The Journal of Educational Research, 103, 227-238. doi: $10.1080 / 00220670903383036$

Mayer, R. (2001). Multi-media learning. Cambridge, UK: Cambridge University Press.

Mayer, R. E., \& Gallini, J.K. (1990). When is an illustration worth ten thousand words? Journal of Educational Psychology, 82, 715-726.

Mayer, R. E., \& Johnson, C. I. (2008). Revising the redundancy principle in multimedia learning. Journal of Educational Psychology, 100, 380. 
This is an author-produced, peer-reviewed version of this article. The final, definitive version of this document can be found online at Journal of Visual Literacy, published by Routledge. Copyright restrictions may apply. doi: 10.1080/1051144X.2019.1611702

THE IMPACT OF VISUAL DISPLAYS FOR LEARNING ACROSS DISCIPLINES

Metros, S. E. (2008). The Educator's role in preparing visually literate learners. Theory into Practice, 47. doi:10.1080/00405840801992264.

*McTigue, E. M. (2009). Does multimedia learning theory extend to middle-school students? Contemporary Educational Psychology, 34, 143-153.doi:10.1016/j.cedpsych.2008.12.003

*Miller, B. W., Cromley, J. G., \& Newcombe, N. S. (2016). Improving diagrammatic reasoning in middle school science using conventions of diagrams instruction. Journal of Computer Assisted Learning, 32, 374-390. doi: 10.1111/jcal.12143

*Moreno, R., Ozogul, G., \& Reisslein, M. (2011). Teaching with concrete and abstract visual representations: Effects on students' problem solving, problem representations, and learning perceptions. Journal of Educational Psychology, 103, 32. doi: $10.1037 / \mathrm{a} 0021995$

*Muthersbaugh, D., Kern, A. L., \& Charvoz, R. (2014). Impact through images: Exploring student understanding of environmental science through integrated place-based lessons in the elementary classroom. Journal of Research in Childhood Education, 28, 313-326.

*Norman, R. R. (2012). Reading the graphics: what is the relationship between graphical reading processes and student comprehension?. Reading and Writing, 25, 739-774.

Paivio, A. (1971). Imagery and verbal processes. New York, NY: Holt, Rinehart \& Winston.

Paivio, A. (1986). Mental representations: A dual coding approach. New York, NY: Oxford University Press.

Pearson, P. D., \& Billman, A. K. (2016). Reading to learn science. In Z., Babaci-Wilhite (Ed.), Human Rights in Language and STEM Education. Netherlands: Sense Publishers. 
This is an author-produced, peer-reviewed version of this article. The final, definitive version of this document can be found online at Journal of Visual Literacy, published by Routledge. Copyright restrictions may apply. doi: 10.1080/1051144X.2019.1611702

THE IMPACT OF VISUAL DISPLAYS FOR LEARNING ACROSS DISCIPLINES

Peeck, J. (1993). Increasing picture effects in learning from illustrated text. Learning and Instruction, 3, 227-238.

Polkinghorne, D. E. (1995). Narrative configuration in qualitative analysis. International Journal of Qualitative Studies in Education, 8, 5-23.

*Pyke, C. L. (2003). The use of symbols, words, and diagrams as indicators of mathematical cognition: A causal model. Journal for Research in Mathematics Education, 34, 406-432. doi: $10.2307 / 30034794$

Renkl, A., \& Scheiter, K. (2017). Studying visual displays: How to instructionally support learning. Educational Psychology Review, 29, 599-621. doi: 10.1007/s10648-015-9340-4

Rimrodt, S., Lightman, A., Roberts, L., Denckla, M. B., \& Cutting, L. E. (2005, February). Are all tests of reading comprehension the same? Paper presented at the 33rd Annual International Neuropsychological Society Meeting.

Risko, V. J., Roller, C. M., Cummins, C., Bean, R. M., Block, C. C., Anders, P. L., \& Flood, J. (2008). A critical analysis of research on reading teacher education. Reading Research Quarterly, 43, 252-288. doi: 10.1598/RRQ.43.3.3

Roberts, K. L., \& Brugar, K. A. (2017). The view from here: Emergence of graphical literacy. Reading Psychology, 38, 733-777. doi:10.1080/02702711.2017.1336661

Robinson, R. S. (1984). Learning to see: Developing visual literacy through film. Top of the News, 40, 267-275.

*Roberts, K. L., Norman, R. R., \& Cocco, J. (2015). Relationship between graphical device comprehension and overall text comprehension for third-grade children. Reading 
This is an author-produced, peer-reviewed version of this article. The final, definitive version of this document can be found online at Journal of Visual Literacy, published by Routledge. Copyright restrictions may apply. doi: 10.1080/1051144X.2019.1611702

THE IMPACT OF VISUAL DISPLAYS FOR LEARNING ACROSS DISCIPLINES

Psychology, 36, 389-420. doi: 10.1080/02702711.2013.865693

Sadoski, M., Goetz, E. T., Stricker, A. G., \& Burdenski, T. K. (2003). New findings for concreteness and imagery effects in written composition. Reading and Writing, 16, 443453.

*Schmeck, A., Mayer, R. E., Opfermann, M., Pfeiffer, V., \& Leutner, D. (2014). Drawing pictures during learning from scientific text: Testing the generative drawing effect and the prognostic drawing effect. Contemporary Educational Psychology, 39, 275-286. doi: 10.1016/j.cedpsych.2014.07.003

*Segers, E., Verhoeven, L., \& Hulstijn-Hendrikse, N. (2008). Cognitive processes in children's multimedia text learning. Applied Cognitive Psychology, 22, 375-387.

Shanahan, T., \& Shanahan, C. (2008). Teaching disciplinary literacy to adolescents: Rethinking content-area literacy. Harvard Educational Review, 78, 40-59.

*Sun, J. C. Y., \& Chen, A. Y. Z. (2016). Effects of integrating dynamic concept maps with Interactive Response System on elementary school students' motivation and learning outcome: The case of anti-phishing education. Computers \& Education, 102, 117-127. doi: 10.1016/j.compedu.2016.08.002

*Sun, J. C. Y., \& Lee, K. H. (2016). Which teaching strategy is better for enhancing antiphishing learning motivation and achievement? The concept maps on tablet PCs or worksheets?. Journal of Educational Technology \& Society, 19, 87.

*Swanson, H. L. (2015). Cognitive strategy interventions improve word problem solving and working memory in children with math disabilities. Frontiers in Psychology, 6, 1099. 
doi: 10.3389/fpsyg.2015.01099

*Swanson, H. L., Lussier, C., \& Orosco, M. (2013). Effects of cognitive strategy interventions and cognitive moderators on word problem solving in children at risk for problem solving difficulties. Learning Disabilities Research \& Practice, 28, 170-183. doi:

10.1111/ldrp.12019

*Terwel, J., van Oers, B., van Dijk, I., \& van den Eeden, P. (2009). Are representations to be provided or generated in primary mathematics education? Effects on transfer. Educational Research and Evaluation, 15, 25-44. doi: 10.1080/13803610802481265

Vacca, R. T., Vacca, J. A. L., \& Mraz, M. E. (2005). Content area reading: Literacy and learning across the curriculum. England: Pearson

*Van Garderen, D. (2006). Spatial visualization, visual imagery, and mathematical problem solving of students with varying abilities. Journal of Learning Disabilities, 39, 496-506. doi: $10.1177 / 00222194060390060201$

*Van Garderen, D. (2007). Teaching students with LD to use diagrams to solve mathematical word problems. Journal of Learning Disabilities, 40, 540-553.

Vekiri, I. (2002). What is the value of graphical displays in learning?. Educational Psychology Review, 14, 261-312.

Vinter, A., \& Perruchet, P. (2000). Implicit learning in children is not related to age: Evidence from drawing behavior. Child Development, 71, 1223-1240.

Waller, R. (1981). Understanding network diagrams. Paper presented at the Annual Meeting of the American Educational Research Association, Los Angeles, April 1981. 
This is an author-produced, peer-reviewed version of this article. The final, definitive version of this document can be found online at Journal of Visual Literacy, published by Routledge. Copyright restrictions may apply. doi: 10.1080/1051144X.2019.1611702

*Wang, H. Y., Huang, I., \& Hwang, G. J. (2016). Effects of a question prompt-based concept mapping approach on students' learning achievements, attitudes and 5C competences in project-based computer course activities. Journal of Educational Technology \& Society, $19,351$.

Watkins, N. M., \& Lindahl, K. M. (2010). Targeting content area literacy instruction to meet the needs of adolescent English language learners. Middle School Journal, 4, 23-33.

Wileman, R. E. (1993). Visual communicating. Englewood Cliffs, NJ: Educational Technology Publications.

*Zheng, R. Z., Yang, W., Garcia, D., \& McCadden, E. P. (2008). Effects of multimedia and schema induced analogical reasoning on science learning. Journal of Computer Assisted Learning, 24, 474-482. doi: 10.1111/j.1365-2729.2008.00282.x 
1677 articles located during initial search in the following databases: PsycInfo; Eric; Education Source. We searched the articles published between January, 2002 and October, 2017. The following inclusion criteria was used during the initial search:

(a) Examined empirically;

(b) Published in a peer-reviewed journal;

(c) Measured students' cognitive learning process and/or outcomes;

(d) Conducted in K-12 education context;

(e) Involved a graphic task;

(f) Primarily focus on the use of graphics across disciplines;

(g) Studies used video, audio, simulation, and computer games were excluded.

189 articles screened for full view

173 articles retained after abstract level screening and removing duplicated articles

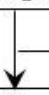

88 articles retained for full view and coding using Methodological Quality Indicators (MQIs)

Finally, 44 articles retained for inclusion in analysis
1504 articles were discarded as not meeting the inclusion criteria as follows:

(a) Empirical study $(\mathrm{n}=17)$

(b) Not peer review $(n=0)$

(c) Did not measured students' cognitive learning $(n=29)$

(d) Not $\mathrm{K}-12$ students $(\mathrm{n}=63)$

(e) Not graphic task $(n=1238)$

(f) Graphics are not the primary focus of the study $(n=81)$

(g) Studies used video, audio, simulation, and computer games were excluded $(n=76)$

16 articles meet the inclusion criteria after an ancestral search

101 articles discarded as not meeting the inclusion criteria as follows:

1. Empirical study $(n=2)$

2. Not peer review $(n=2)$

3. Did not measured students ${ }^{2}$ cognitive learning $(\mathrm{n}=16)$

4. Not K-12 students $(n=12)$

5. Not graphic task $(n=6)$

6. Graphics are not the primary focus of the study $(n=44)$

7. Studies used video, audio, simulation, and computer games were excluded $(n=9)$

Figure 1. Article retrieval and identification process 


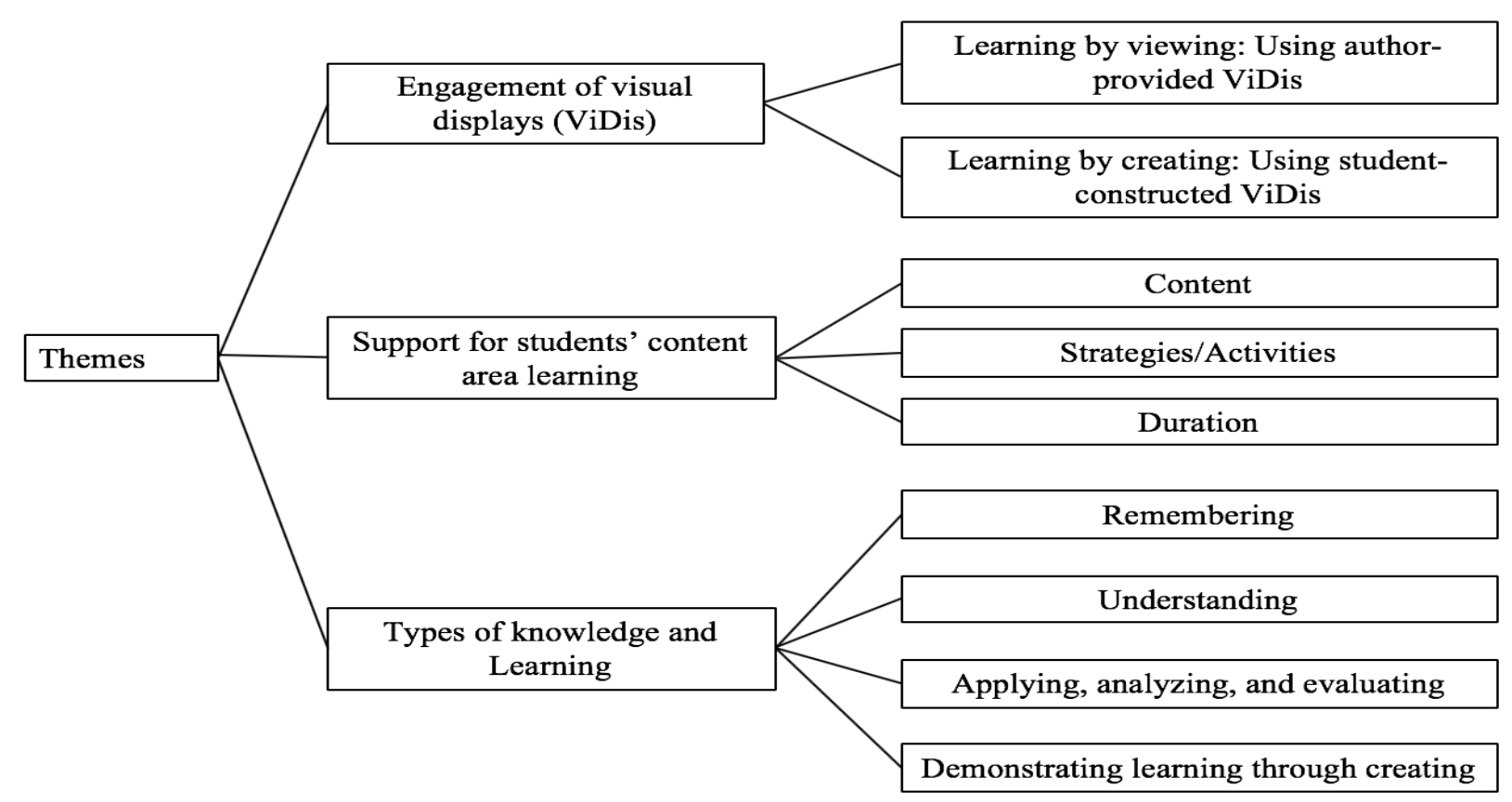

Figure 2. The hieratical structure of the themes 